\title{
European guidance on drug-resistant tuberculosis in children and adolescents
}

The age-specific challenges for tuberculosis prevention and care in children and adolescents are increasingly recognised. ${ }^{1,2}$ However, addressing these challenges still requires greater focus by national tuberculosis programmes and increased public health prioritisation. ${ }^{3}$

This matter is as relevant in the WHO European region as in the rest of the world. ${ }^{4}$ The challenges are even more pronounced when addressing the multidrugresistant tuberculosis epidemic, with multidrug-resistant organisms defined as those resistant to the two most effective first-line antibiotics: rifampicin and isoniazid. The prevention, detection, and treatment of multidrugresistant tuberculosis in this vulnerable young population requires specific guidance, training, and investment.

The global burden of multidrug-resistant tuberculosis is increasing and most cases are now caused by transmission of already resistant organisms. ${ }^{5}$ The WHO European region accounts for $23 \%$ of the global multidrug-resistant tuberculosis disease burden for all age groups, ${ }^{6}$ and 2120 children (aged $<15$ years) were estimated to develop multidrug-resistant tuberculosis disease in the region in $2017^{7}$ (appendix). Most of these cases originated from 18 high-priority European countries. Given that less than $5 \%$ of children with multidrug-resistant tuberculosis are diagnosed and treated, ${ }^{8}$ nearly 2000 children in the region remain undiagnosed each year. This number does not include adolescents aged 15 to 19 years who contribute a substantial additional burden. In addition to this large undiagnosed multidrug-resistant tuberculosis disease burden, a 2019 modelling paper suggested that in the WHO European region, $14.1 \%$ of children with tuberculosis infection were infected with multidrugresistant strains, the highest proportion in the world. ${ }^{9}$ This population represents a vast reservoir of future multidrugresistant tuberculosis cases that will contribute to ongoing transmission and propagation of the epidemic.

In recognition of these challenges, the WHO Regional Office for Europe has launched an expert opinion document dedicated to the regional response to multidrug-resistant tuberculosis in children and adolescents. ${ }^{10}$ The aim of this document is to guide Member States to adequately address multidrugresistant tuberculosis among this young and vulnerable population within their respective tuberculosis programmes. It provides a review of the existing literature related to diagnosis and management of child and adolescent multidrug-resistant tuberculosis with a specific focus on the WHO European Region. The document features a section on resources that are available for the clinician faced with difficult-to-treat cases, and refers to other practical guidelines for dayto-day management of children and adolescents with multidrug-resistant tuberculosis.

The guidance document suggests that various key elements are necessary to improve reporting, diagnosis, and treatment of multidrug-resistant tuberculosis in children and adolescents. All cases should be registered through individual electronic reporting throughout the entire WHO region, and all treatment outcomes should be reported. These data could inform future treatment strategies. To diagnose infection in children and adolescents exposed to multidrug-resistant tuberculosis, in line with existing WHO guidelines, contact tracing should be used routinely and rigorously, and tests for infection, such as tuberculin skin tests or interferon gamma release assays, should be used where available. To establish tuberculosis disease diagnosis, all efforts should be made to confirm tuberculosis bacteriologically, and to establish a drug-susceptibility profile. However, a clinical diagnosis without bacteriological confirmation might commonly be needed in younger children, with a treatment regimen constructed based on the drug resistance pattern of the source case.

This joint expert and WHO guidance document suggests that all household contacts of multidrugresistant tuberculosis should be evaluated for tuberculosis and, if found to be well, a risk assessment should be carried out to judge the risk of future disease progression. The evidence base around the efficacy and safety of available treatment regimens for multidrugresistant tuberculosis infection is increasing; these regimens can now be considered by clinicians for highrisk contacts. For the treatment of multidrug-resistant tuberculosis disease, the document recommends an all-oral regimen to avoid the use of regular injections. At least four effective drugs should be used at the
Lancet Child Adolesc Health 2019 Published Online October 29, 2019 https://doi.org/10.1016/ S2352-4642(19)30332-3 
beginning of treatment (composed of WHO group $\mathrm{A}$ and $B$ drugs), with delamanid used if needed to construct an adequate regimen. Currently, data are scarce on the use of bedaquiline in children under 6 years and on the use of delamanid in children younger than 3 years. ${ }^{11}$

This guidance document also emphasises the importance of integrating tuberculosis care within the wider health-care system for children and adolescents. The traditional, vertical structure of tuberculosis programmes should be complemented by an integrated, comprehensive approach featuring universal health coverage and intersectoral collaboration. Finally, within the European region, research and development needs to be promoted, and child and adolescent tuberculosis, both drug-susceptible and drug-resistant, need to be further prioritised in the regional response at the highest level. A need exists to develop better nonsputum-based diagnostic tests for tuberculosis in the youngest children and more accurate tests of infection that predict which children and adolescents will progress to disease in the future. The evidence base around treatments for multidrug-resistant tuberculosis needs to develop and new drugs and regimens for children and adolescents with MDR-TB are required. Novel vaccines for use in these age groups are urgently needed. It is only through new scientific discoveries combined with optimised and integrated implementation of existing best practice, that the ambitious End TB goals, set by WHO, will be achieved.

\section{Matthias I Gröschel, James A Seddon, Satria A Prabowo, Giovanni B Migliori, Stephen M Graham, \\ Martin van den Boom, *Masoud Dara}

Joint TB, HIV and Viral Hepatitis Programme, Division of Health Emergencies and Communicable Diseases, WHO Regional Office for Europe, UN City, 2100 Copenhagen Ø, Denmark (MIG, MvdB, MD); Department of Biomedical Informatics, Harvard Medical School, Boston, MA, USA (MIG); Section of Paediatric Infectious
Diseases, Department of Infectious Diseases, Imperial College London, London, UK (JAS); Desmond Tutu TB Centre, Department of Paediatrics and Child Health, Stellenbosch University, Stellenbosch, South Africa (JAS); Faculty of Infectious and Tropical Diseases, London School of Hygiene \& Tropical Medicine, London, UK (SAP); Istituti Clinici Scientifici Maugeri Istituto di Recovero e Cura a Carattere Scientifico, Tradate, Italy (GBM); Centre for International Child Health, Department of Paediatrics, University of Melbourne, Melbourne, Australia (SMG); Murdoch Children's Research Institute, Melbourne, Australia (SMG); and International Union Against Tuberculosis and Lung Disease, Paris, France (SMG) daram@who.int

We declare no competing interests. The authors would like to thank Peter Dodd for producing the figure. JAS is supported by a Clinician Scientist Fellowship jointly funded by the UK Medical Research Council (MRC) and the UK Department for International Development (DFID) under the MRC/DFID Concordat agreement (MR/R007942/1).

Copyright $\odot$ 2019. World Health Organization. Published by Elsevier Ltd/Inc/BV All rights reserved.

1 Marais BJ, Graham SM, Maeurer M, Zumla A. Progress and challenges in childhood tuberculosis. Lancet Infect Dis 2013; 13: 287-89.

2 Sandgren A, Cuevas LE, Dara M, et al. Childhood tuberculosis: progress requires an advocacy strategy now. Eur Respir J 2012; 40: 294-97.

3 Gröschel MI, van den Boom M, Migliori GB, Dara M. Prioritising children and adolescents in the tuberculosis response of the WHO European Region. Eur Respir Rev 2019; 28: 180106

4 Acosta CD, Rusovich V, Harries AD, Ahmedov S, van den Boom M, Dara M. A new roadmap for childhood tuberculosis. Lancet Glob Health 2014; 2: e15-17.

5 WHO. Global tuberculosis report 2018. Geneva: World Health Organization 2018

6 WHO Regional Office for Europe, European Centre for Disease Prevention and Control. Tuberculosis surveillance and monitoring in Europe 20192017 data. World Health Organization. 2019. https://ecdc.europa.eu/sites/ portal/files/documents/tuberculosis-surveillance-monitoringEurope-2019-20_Mar_2019.pdf (accessed July 15, 2019).

7 Dodd PJ, Sismanidis C, Seddon JA. Global burden of drug-resistant tuberculosis in children: a mathematical modelling study. Lancet Infect Dis 2016; 16: 1193-201.

8 Jenkins $\mathrm{HE}$, Yuen $\mathrm{CM}$. The burden of multidrug-resistant tuberculosis in children. Int J Tuberc Lung Dis 2018; 22: 3-6.

9 Knight GM, McQuaid CF, Dodd PJ, Houben RMGJ. Global burden of latent multidrug-resistant tuberculosis: trends and estimates based on mathematical modelling. Lancet Infect Dis 2019; 19: 903-12.

10 WHO Regional Office for Europe. Multidrug-resistant tuberculosis in children and adolescents in the WHO European Region: expert opinion. https://apps.who.int/iris/handle/10665/329395 (accessed Oct 18, 2019)

11 WHO. WHO consolidated guidelines on drug-resistant tuberculosis treatment. World Health Organization. 2019. https://apps.who.int/iris/ bitstream/handle/10665/311389/9789241550529-eng.pdf?ua=1 (accessed July 15, 2019). 


\section{University Library}

\section{- M M N E R VA A gateway to Melbourne's research publications}

Minerva Access is the Institutional Repository of The University of Melbourne

Author/s:

Groschel, MI;Seddon, JA;Prabowo, SA;Migliori, GB;Graham, SM;van den Boom, M;Dara, M

Title:

European guidance on drug-resistant tuberculosis in children and adolescents

Date:

2020-01-01

Citation:

Groschel, M. I., Seddon, J. A., Prabowo, S. A., Migliori, G. B., Graham, S. M., van den Boom, M. \& Dara, M. (2020). European guidance on drug-resistant tuberculosis in children and adolescents. LANCET CHILD \& ADOLESCENT HEALTH, 4 (1), pp.9-11. https:// doi.org/10.1016/S2352-4642(19)30332-3.

Persistent Link:

http://hdl.handle.net/11343/246514 